Research Article

\title{
Application of Green Building Design Based on the Internet of Things in the Landscape Planning of Characteristic Towns
}

\author{
Ying Xu $\mathbb{1}^{1,2}$ \\ ${ }^{1}$ Department of Information Engineering, Guangxi International Business Vocational College, Nanning 530000, Guangxi, China \\ ${ }^{2}$ College of Art, Suan Sunandha Raiabhat University, Bangkok 10300, Thailand
}

Correspondence should be addressed to Ying Xu; 20131297@huanghuai.edu.cn

Received 23 April 2021; Revised 25 May 2021; Accepted 16 June 2021; Published 28 June 2021

Academic Editor: Sang-Bing Tsai

Copyright (c) 2021 Ying Xu. This is an open access article distributed under the Creative Commons Attribution License, which permits unrestricted use, distribution, and reproduction in any medium, provided the original work is properly cited.

China is a large agricultural country. In the past, relying on the accumulation of agriculture and the contribution of farmers, it laid a solid foundation for China's economic construction. However, with the improvement of the national economy and industrialization system, the dual structure of urban and rural areas has become more and more obvious, and the broad masses of farmers have not enjoyed the fruits of industrialization and urbanization. Based on the theoretical research on green rural dwellings, drawing lessons from relevant theories and cases at home and abroad, this paper proposes green rural construction techniques suitable for northern China and studies how to participate in the whole process of rural construction in an all-round way. In the middle and late stages, green concepts should be integrated, especially considering the feasibility of three-star farmhouse standards, from land saving (land planning), energy saving (environmental protection structure, heating, ventilation, and new energy utilization), water saving (rainwater collection and greening), material saving (resource reuse and on-site materials), and indoor environmental quality control (noise control and anticondensation), these five aspects are used to design buildings. The deformation monitoring system can monitor the deformation of agricultural building structures in real time. The experimental results show that the Internet-based agricultural building deformation monitoring system studied in this paper can perform real-time deformation monitoring of various agricultural buildings, thereby improving the safety of agricultural buildings and ensuring agriculture the safety of production, and transportation plays an important role in the protection and accumulation of agricultural information loss. The service life of the building is increased by at least $30 \%$. It is hoped that the research results in this article can provide guidance and reference for the construction and planning of beautiful rural areas. In the future, the construction of beautiful villages will be more beautiful and more distinctive.

\section{Introduction}

With the increasing global energy shortage, countries are paying more and more attention to energy conservation. The energy efficiency of buildings is an important technical field of the global construction industry, and it is also an effective development approach to reduce global energy shortages and improve environmental quality. In Western industrialized countries, the composition of social energy consumption mainly includes industrial energy consumption, transportation energy consumption, and political energy consumption, while political energy consumption is mainly based on energy consumption. Building energy consumption in Western industrialized countries accounts for $30 \%$ to $40 \%$ of the country's total energy consumption, such huge building energy consumption will definitely cause damage to the environment. Therefore, building energy efficiency work is related to social progress and economic development decisions. The energy consumption index of public buildings is very high, which has great potential for energy-saving renovation. At the same time, the renovation of large public buildings has strong operability, and the construction is much easier than the renovation of residential buildings. For large public buildings, they are generally urban administrative office facilities and even some urban landmark buildings. If reasonable energy-saving 
renovation of public buildings can be carried out, it will greatly promote the energy-saving standards, management methods, policy standards, and so on of building renovations, thereby guiding the green energy-saving renovation of existing public buildings nationwide.

Ren et al. believed that the development of green buildings and their technologies is the best choice to solve the problem of resource consumption and pollution caused by China's current rapid urbanization, especially the current prosperous typical cities. Environmentally friendly building technology is guided and supported, the important role and status of green building technology in typical cities are analyzed, the related applications of green building technology in typical city construction are briefly analyzed, and in-depth promotion and strategies of green building technology in typical buildings detailed research are conducted. New ideas are provided through this application and environmentally friendly building technologies are used in typical urban buildings. However, whether green buildings need to introduce more financial support, and whether the development will lag behind, Ren et al. did not answer this question [1]. For the application of green buildings, experts at home and abroad also have many studies. Puliqun pointed out that the national rural revitalization strategy pointed out the direction of rural development in the new era, and the constructions of beautiful villages, pastoral complexes, and characteristic towns were the most important carriers of rural revitalization. The construction of characteristic towns should not only develop characteristic industries, attract population, and undertake the spillover of urban consumption but also inherit and promote regional and national characteristics [2]. Xiao et al. said that green building is already a wellknown concept, but it is not easy to implement "green" into the design and operation of the formal space in actual projects to improve the overall quality of the building [3]. BartPoel's design integration theory is relatively mature, and it introduces the entire process of personnel construction and the application process of integration thinking. The concept of integrated design is also in line with the concept of green building design. At the same time, green buildings can be better realized through integrated design theory [4].

To ensure data reliability and save costs, the use of Internet of Things technology for building deformation monitoring can realize the intelligent collection and transmission of data, can reduce the error of manual deformation monitoring, can realize the automatic monitoring of the health status of the building, and save the consumption of building deformation monitoring manpower, material resources, and time [5]. Then, there is the meaning of science and technology. The analysis of the large amount of building deformation information collected will help to fundamentally understand the principle of building deformation, can provide technical and normative basis for engineering design, and can also form construction industry design, specifications, and standards for construction and maintenance [6]. At the same time, advanced data processing methods such as machine learning and deep neural networks can be used to analyze a large amount of collected data, establish an effective deformation prediction model, and improve the safety of the building. Finally, the real-time deformation monitoring of agricultural buildings using Internet of Things technology is conducive to improving the safety of agricultural production, transportation, and storage, speeding up the construction of China's agricultural infrastructure informatization and also conducive to the realization of China's agricultural informatization $[7,8]$.

\section{Implementation Methods for Green Building of the Internet of Things}

2.1. Close-Range Photogrammetry Technology. However, the conventional building deformation monitoring method requires a lot of work and takes a long time. The monitoring points set on the monitoring objects are easily affected by the local topography. At the same time, the conventional measuring instruments require manual observation and measurement, which are affected by human factors. The objectivity of each monitoring data cannot be guaranteed, and manual recording is required in the recording of deformation data, which results in a high probability of error. For the deformation monitoring of the whole life cycle of the building, conventional monitoring methods can only collect the deformation information of the building at a certain moment, and the transmission of the deformation data also has a large lag, and it is impossible to do real-time deformation monitoring of the building $[9,10]$.

Close-range photogrammetry technology is to use image acquisition equipment to photograph the target object and obtain the shape, form, and geometric position information of the object, and the measurement accuracy can reach the millimeter level $[11,12]$. In recent years, photogrammetry technology has been widely used in structural deformation monitoring such as high-rise building deformation, bridge vibration response, dam structural deformation, and landslides. Close-range photogrammetry technology has the following advantages in building deformation monitoring:

(1) The geometric information of the monitored building and the distance between the monitoring point can be accurately recorded in an instant $[13,14]$;

(2) There is no requirement for the shape of the monitored object, which is suitable for the overall and partial deformation monitoring of regular and irregular buildings;

(3) The monitored object information on the photo is rich and objective and can be stored for a long time, which is conducive to the analysis of the deformation trend of the building;

(4) Noncontact Information Collection Process. The operation is simple, the measurement is fast, it will not affect the building itself, nor will it pose a security 
threat to the information collection personnel $[15,16]$.

Due to its advantages in information collection accuracy, data storage, and analysis, digital photogrammetry will have a good application prospect in the field of building deformation monitoring $[17,18]$. However, photogrammetry requires relatively high equipment resolution, relatively expensive equipment, and complex data analysis algorithms. It is not suitable for real-time building deformation monitoring data collection that requires a long time. Figure 1 shows a rural water tower.

2.2. Research Methods and Technical Routes. This article aims to analyze the policy theory of characteristic towns, extract theoretical guidance suitable for the construction planning of beautiful villages, and use the relevant policy connotations of characteristic towns to lead the construction planning of beautiful villages, making the construction planning of beautiful villages more beautiful and more distinctive $[19,20]$.

(1) Documentary Materials Law. Reading, collecting, and sorting out information obtained from books, periodicals, the Internet, and television broadcasting, to understand the current achievements in the field of green building at home and abroad. The concepts are studied in-depth. First, we will study the relevant theoretical concepts in depth and then organize them on this basis to form a scientific understanding of the things themselves and lay a solid theoretical foundation for the design of rural green buildings [21].

(2) Field Investigation Method. Field investigation and investigation of Qiwangfen Village, door-to-door interviews, street visits, and so on to understand the local natural conditions, economic level, and living conditions, master a large amount of first-hand information, and conduct research. The collation and analysis of information and local historical records establish a scientific research basis and provide a reasonable direction for the next step in the selection of technical means.

(3) Comparative Analysis Method. In the planning stage, comparative analysis of policies and regulations, villagers' wishes, planning conditions, and so on should be carried out, and plans with relative advantages should be selected. In the design stage, through comparative analysis of structural forms, from the perspective of stability, cost, and availability, the final structural plan was compared and selected in several aspects of sustainability, including the choice of enclosure materials. It also compared the thermal performance, service life, and construction speed of various products from a variety of products and selected low cost and high efficiency. The building products are used in the construction of green rural dwellings.

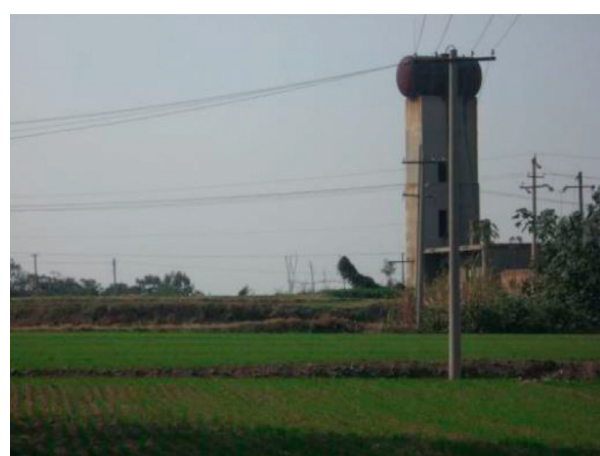

Figure 1: Rural water tower (the picture comes from https://image. baidu.com/).

(4) Inductive Summary Method. An inductive analysis of the previous theories and research data is conducted, then the relevant theories and excellent cases of characteristic towns are combined, and they are refined in a targeted manner, and finally the corresponding theories of characteristic towns are used to lead the construction of beautiful villages [22].

(5) Theoretical analysis method constructs a deformation monitoring system framework based on the Internet of Things technology, the feasibility of the system in principle is analyzed, the wrong design in time is abandoned, waste of research time and funds is avoided, and the data accuracy and data transmission of the system are monitored. Predictions in terms of efficiency, coverage, and power consumption are made.

\section{Correlation Experiment of Agricultural Building Deformation Monitoring System}

3.1. Adaptive Weighted Fusion Algorithm Model. Multisensor data fusion technology is designed for the fusion of environmental information in digital farmland. Due to the large area of farmland, multiple sensor nodes need to be arranged in the same farmland to collect environmental information uniformly. Collection will generate a lot of data. In addition, because most of the farmland is located in a remote geographic environment and its natural environment is also more complex, it is easy to cause interference to the measurement accuracy of the sensor. If a large amount of information is transmitted at the same time, the energy consumption will also affect the sensors. The acquisition accuracy has a huge impact $[23,24]$. In order to meet the requirements of the digital farmland information collection system for collection accuracy, this design adopts a datalevel fusion method known for its nondestructive and highperformance processing information to fuse farmland environmental data $[25,26]$. The specific idea is that when the sensor node collects farmland environmental data, it will be transmitted to the nearest LoRa gateway, and then the data will be effectively fused in the microcontroller of the LoRa gateway. At this time, the fused raw data are still without any treatment, and it can effectively eliminate the influence 
caused by interference factors and get very accurate and effective fusion results. The execution steps are shown in Figure $2[27,28]$.

Suppose first that the measured values of $n$ sensors are $X_{1}, X_{2}, X_{3}, \ldots, X_{n}, X$ is the true value of the system to be estimated, and $S_{1}, S_{2}, S_{3}, \ldots, S_{n}$ are the $n$ of the parameters to be measured. These observations of the data are independent of each other and are unbiased estimates of $X[29,30]$. The weights of the weighting factors of each sensor are $W_{1}, W_{2}$, $W_{3}, \ldots, W_{n}$, and the correlation between the value of the fusion result $X$ and the weight is shown in the following formula:

$$
\left\{\begin{array}{l}
X=\sum W_{i} X_{i} \\
\sum_{i=1}^{n} W_{i}=1
\end{array}\right.
$$

If the average value of the actual measurement value of the sensor of the collection terminal is calculated multiple times, the influence of the noise value on the calculation result will become smaller and smaller, which will cause the calculation result to gradually approach the true value infinitely. According to this idea, the fusion idea of the improved multisensor adaptive weighted fusion algorithm can be realized through the following steps [31]:

The total mean square error $Q$ is as follows:

$$
\begin{gathered}
Q=E\left[\left(X-X_{1}\right)\right], \\
E\left[\sum_{i=1}^{n} W_{i} X-\sum_{i=1}^{n} W X_{i}\right] .
\end{gathered}
$$

As explained above, the values of $X_{1}, X_{2}, X_{3}, \ldots, X_{n}$ are independent of each other and are all unbiased estimates of $X$, so there are the following two formulas [32]:

$$
\left\{\begin{array}{l}
E\left(X-X_{1}\right)\left(X-X_{i}\right)=0, \\
i=1,2 \ldots n .
\end{array}\right.
$$

It can be seen that formula (4) is a multivariate quadratic function of the total mean square error with respect to each weighting factor. From the characteristics of the multivariate quadratic function, it can be known that when the minimum value of the total mean square error $Q$ is obtained, the corresponding weighting factor $W$ is the best weight, so the model can be transformed into the minimum value of the following formula:

$$
\left\{\begin{array}{l}
f\left(W_{i}\right)=\sum_{i=1}^{n} W_{i}^{2} Q \\
\sum_{i=1}^{n} W_{i}=1
\end{array}\right.
$$

Formula (5) can be expressed as the minimum value of $f(w)$ when the conditions are met, and the following functions are constructed using the Lagrangian multiplier method:

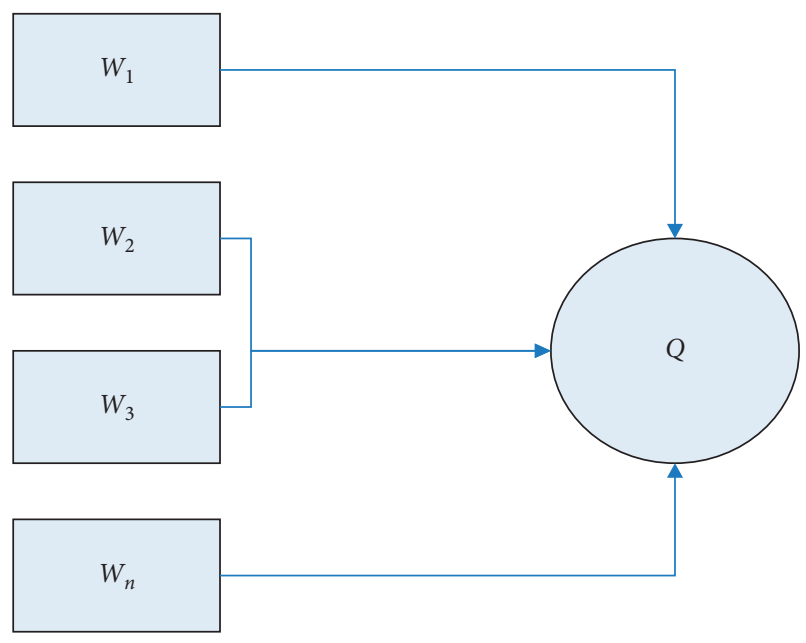

Figure 2: Adaptive weighted fusion structure.

$$
\left\{\begin{array}{l}
F(w)=F\left(w_{i}\right)+\mu\left(w_{i}\right), \\
\mu\left(w_{i}\right)=\sum_{i=1}^{n} w_{i}-\mu .
\end{array}\right.
$$

3.2. Selection of Sensor's Optimal Variance Value. In the basic calculation steps of the adaptive weighted fusion algorithm, it can be known that the data fusion accuracy obtained by the adaptive weighted fusion algorithm is closely related to the number of sensors and the number of fusions. Considering that in the process of measuring farmland information, too many external factors will affect the accuracy of the collected data [33]. In order to further improve the accuracy of farmland information fusion, this design proposes an improved adaptive weighted fusion algorithm based on the adaptive weighted fusion algorithm. The rural Internet of Things is shown in Figure 3.

Incorporating formula (2) into formula (6) and calculating the partial derivatives of $W$, respectively, the value of the minimum total mean square error obtained at this time is as follows [34]:

$$
Q^{2}=\frac{1}{\sum_{i=1}^{n}\left(1 / Q^{2}\right)} .
$$

The estimated value is as follows:

$$
X=\sum_{i=1}^{n} W_{i} X(K) .
$$

When the value $X$ obtained after fusion is constant, it can be estimated based on the average value of the historical data of each sensor. The mean value of $k$ times measured by the sensor is as follows:

$$
X_{i}(k)=\frac{1}{k} \sum_{j=1}^{k} X_{j}(j) .
$$

Let $V(i), Y(i)$, and $Z(i)$, respectively, represent the actual measurement value of the sensor of the collection 


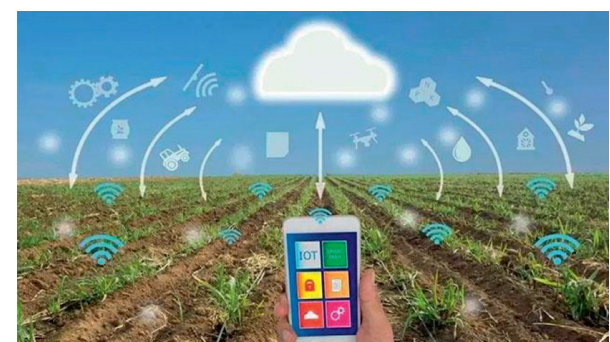

Figure 3: Rural picture of the Internet of Things (picture from http://www.nltown.com/news/pingtai/194.html).

terminal, the initial value of the sensor of the collection terminal, and the noise value that affects the accuracy of the collection, so the following formula can be obtained:

$$
V(i)=Y(i)+Z(i)
$$

Since there are different types of farmland information to be measured and the value measured in each time period is different, the initial value of each sensor is also different. Therefore, the actual measurement value $V(i)$ of the terminal sensor is divided into two parts, and the influence of noise on the sensor of the collection terminal in different time periods and different environments is a random process, so the noise interference can be regarded as the same value [35], as follows:

$$
\left\{\begin{array}{l}
V_{i}=Y_{i}+Z(i), \\
V(1)=Y(1)+Z(1) .
\end{array}\right.
$$

It can be seen from equation (11) that if the average value of the actual measurement value of the sensor of the collection terminal is calculated multiple times, the influence of the noise value $Z(i)$ on the calculation result will become smaller and smaller, which will cause the calculation result to gradually become true. The value is approaching infinitely. According to this idea, the fusion idea of the improved multisensor adaptive weighted fusion algorithm can be realized through the following steps:

$$
X_{0}=\frac{X_{\max }+X_{\min }}{2} .
$$

Continue to perform subsequent calculations so that the value of the total mean square error $Q$ obtained will be more accurate, the weighting factor $W$ will be better, and the fusion result will be more accurate.

After the correct configuration of each module is completed and the debugging is passed, after the network configuration of the entire system, a complete environmental monitoring and control system is established. We can collect environmental data through the mobile app on the system and the software on the computer. The degree of influence of several control devices on environmental parameters such as water saving, humidity, light intensity, and air quality can be given, as shown in Table 1:

\section{Green Building Design in the Landscape Planning of Characteristic Towns}

4.1. Concept and Technology of Green Building. With the emergence of environmental problems and the outbreak of the energy crisis, the concept and technical methods of green buildings have begun to receive widespread attention. Western countries in Europe and the United States have adopted a series of policies and regulations to advocate the use of new materials, new technologies, and new processes in buildings so that buildings can meet normal use while minimizing natural resources. The earliest designers used green building technology in detached houses to improve the indoor thermal environment and enhance the natural lighting of the building to achieve the purpose of energy saving (Table 2).

The current "Green Building Evaluation Standard" is a national standard, numbered GB/T50378-2019, and will be implemented on August 1, 2019. The evaluation system of the new version of "Green Building Evaluation Standards" is divided into two parts: design evaluation and operation evaluation. It consists of seven categories of indicators: land conservation and outdoor environment, energy conservation and energy utilization, water conservation and water resource utilization, material conservation and material resource utilization, indoor environmental quality, construction management, and operation management. It consists of seven types of indicators: land saving and outdoor environment, energy saving and energy utilization, water saving and water resource utilization, material saving and material resource utilization, indoor environment quality, construction management, and operation management. The weights of various indicators of green buildings are shown in Table 3.

It can be seen from Table 3 that the number and area of green buildings in hot summer and cold winter areas are the most in all climate zones. Among the various building types, the green building signs in public buildings are the most, among all provinces and cities. Jiangsu Province has the largest number of green buildings, nearly twice the number of existing green buildings in Guangdong Province.

As shown in Figure 4, in the building envelope, although the proportion of the area occupied by the external window is only $1 / 3 \sim 1 / 5$, its heat loss accounts for about $40 \%$ of the heat loss of the envelope structure. The heat transfer coefficient, air tightness of the window, the orientation of the window, and the ratio of window to wall are all important factors that affect the heat loss of the window. The green building technologies that can be prioritized in exterior wall renovation mainly include heat preservation and heat insulation technologies.

External wall thermal insulation technology includes three types: internal thermal insulation, external thermal insulation, and self thermal insulation. For the external walls of existing public buildings, the base wall is generally not removed during renovation. Therefore, external wall internal thermal insulation and external wall external thermal 
TABle 1: Degree of influence of environmental parameters.

\begin{tabular}{llccrrr}
\hline & & \multicolumn{3}{c}{ Controlling device } \\
& & Roller blind & Wet curtain & Fill light & Water pump & Fan \\
\hline \multirow{3}{*}{ Environmental parameters } & Water saving & 0.5 & 0.6 & 0.1 & 0.6 & 0.9 \\
& Humidity & 0.9 & 0.1 & 0.6 & 0.1 & 0.1 \\
& Light intensity & 0.3 & 0.9 & 0.1 & 0.9 & 0.3 \\
& Air quality & 0.5 & 0.3 & 0.7 & 0.3 \\
\hline
\end{tabular}

TABLE 2: Green building subindices and key application stages.

\begin{tabular}{lcc}
\hline Project & Subindices & Key application stage \\
\hline Land saving and outdoor environment & Building site & Planning and construction \\
Energy saving and energy utilization & Reduce building energy consumption & Design, construction, operation management \\
Water saving and water resource utilization & Improve water efficiency & Planning, design, operation management \\
Material saving and material resources & Use green building materials & Design, construction, operation management \\
Indoor environmental quality & Indoor air quality & Design, operation management \\
\hline
\end{tabular}

TABLE 3: Various indicators of green building.

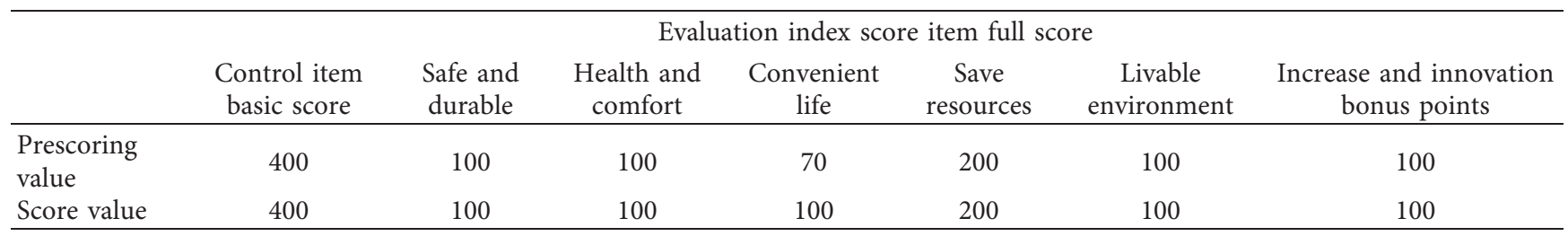

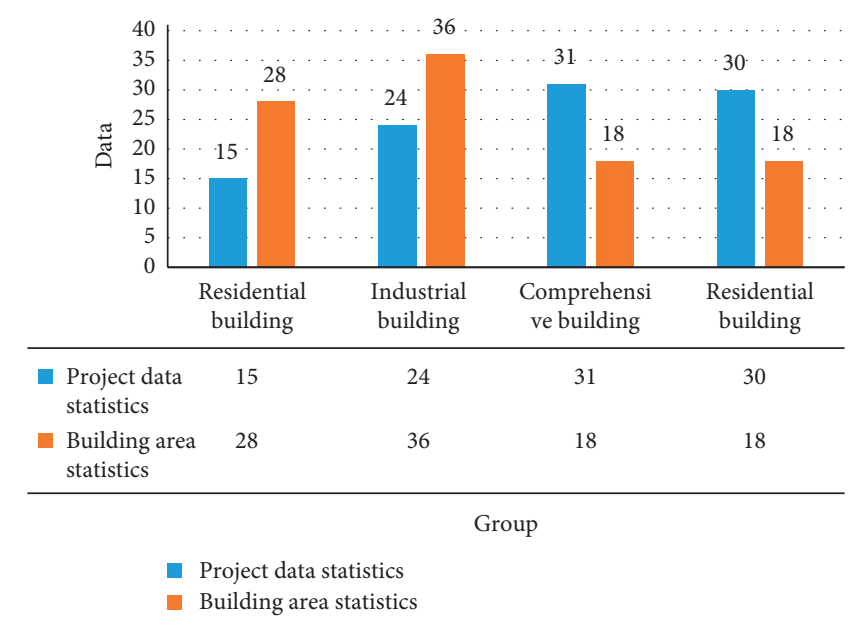

Figure 4: Proportion of green building signs in each climate zone.

insulation are generally used in the green renovation process technology.

The comparison and application of the three thermal insulation technologies are shown in Table 4. Although external wall thermal insulation can also provide thermal insulation in summer, it is necessary not only to adopt thermal insulation technology in hot summer areas but also to take thermal insulation measures to reduce indoor temperature in summer. There is a demand for summer airconditioning in many areas in China. The application of thermal insulation technology for envelope structures can not only improve the indoor thermal environment of buildings but also achieve the purpose of reducing the energy consumption of air-conditioning and cooling in summer. External wall insulation often uses back-ventilated external walls. The hot air in the ventilating layer is lighter in weight. It is discharged from the wall through the air outlet upwards. The air flow will take away external heat and prevent it from being introduced into the room, which can be greatly weakened. The influence of the sun on the wall has greatly reduced the temperature of the inner and outer surfaces of the wall. Back-ventilated external walls generally 
TABle 4: External wall insulation technology.

\begin{tabular}{|c|c|c|}
\hline Practice & Disadvantage & Advantage \\
\hline External wall insulation & $\begin{array}{c}\text { Wide range of application, suitable for different } \\
\text { buildings }\end{array}$ & $\begin{array}{l}\text { The insulation layer is exposed to the outdoors, so it is } \\
\text { easy to stay } \\
\text { Damage, resulting in reduced durability of the material }\end{array}$ \\
\hline $\begin{array}{l}\text { Insulation for external } \\
\text { walls }\end{array}$ & $\begin{array}{r}\text { The insulation layer has } \& \\
\text { avoiding external destruc } \\
\text { protecti }\end{array}$ & $\begin{array}{c}\text { Affected by the surface temperature stress of the external } \\
\text { wall structure layer } \\
\text { Larger influence, easy to induce cracking of the insulation } \\
\text { layer }\end{array}$ \\
\hline $\begin{array}{l}\text { External wall self- } \\
\text { insulation (sandwich } \\
\text { insulation) }\end{array}$ & $\begin{array}{r}\text { ow requirements for } \\
\text { insula }\end{array}$ & $\begin{array}{c}\text { The inner and outer walls need to be connected by } \\
\text { connecting pieces, the structure is relatively complicated, } \\
\text { and the construction technology and process } \\
\text { requirements are high. }\end{array}$ \\
\hline
\end{tabular}

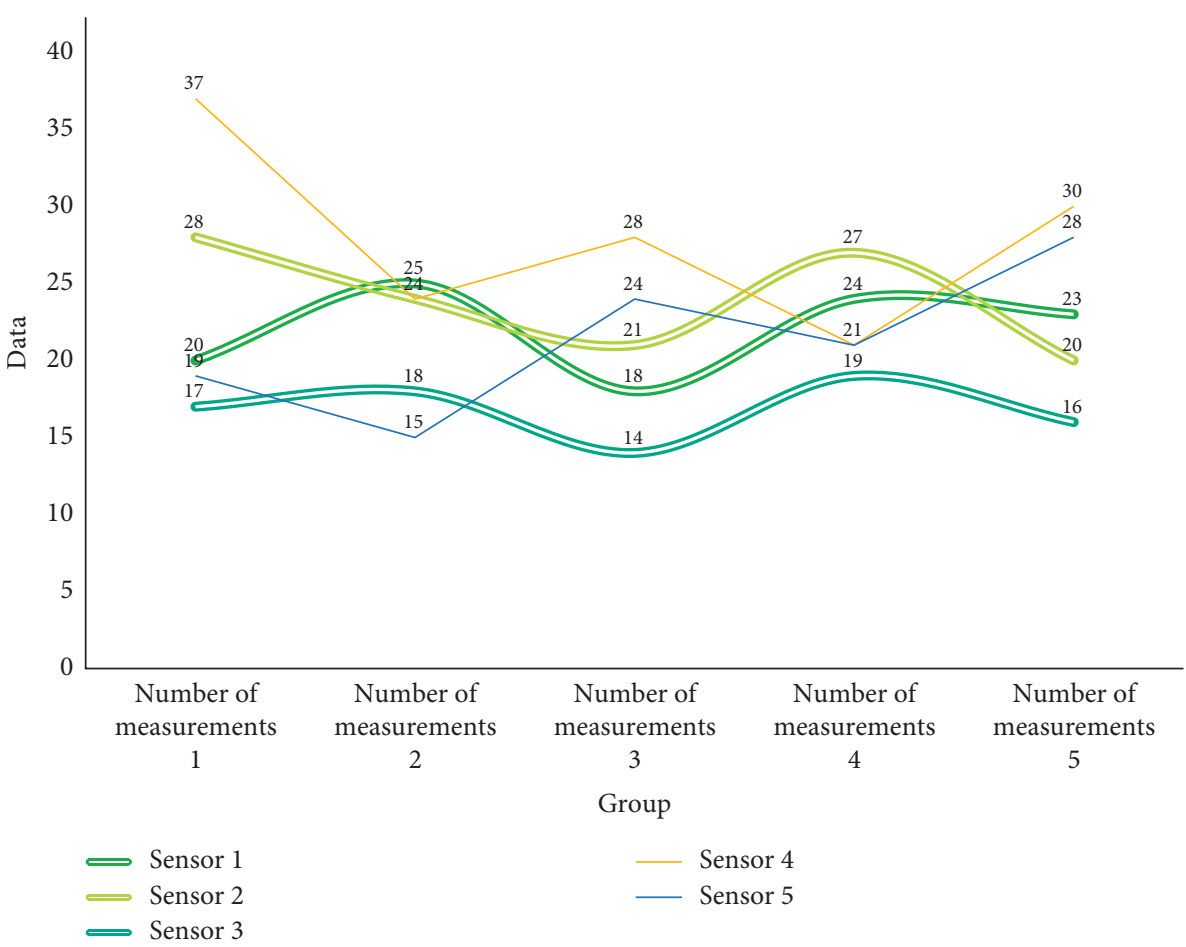

Figure 5: Soil temperature fusion result.

adopt new wall materials with better thermal insulation properties for the base wall, such as aerated concrete, or add thermal insulation materials to the outside of walls with poor thermal insulation properties such as concrete. The backventilated exterior wall structure is relatively complicated, and the cost is relatively high. It is suitable for public buildings. For example, the back-ventilated exterior wall is used in the reconstruction project of Nanjing Landsea International Block.

As shown in Figure 5, in order to verify the feasibility of the algorithm, the arable land information tracking data are compared by experiments. During the experiment, the sensor nodes are evenly distributed in the field, and 5 sensor nodes are arranged. Each node group can record the on-site airtemperature and humidity, soil temperature, air humidity, and light intensity.
4.2. Sensor Selection and Related Circuit Design. The agricultural building deformation monitoring system designed in this paper is an acceleration sensor (the inclination sensor is actually an acceleration sensor that uses the law of inertia) to collect deformation data. Since this article is aimed at the monitoring of the overall structural deformation of the building, how to capture the signal of the small deformation of the building structure is the key, so the selected sensor requires high accuracy.

As shown in Figure 6, the digital output motion sensor MPU605 is selected not only because of its measurement accuracy but also because the digital output sensor can simplify the system hardware design and facilitate the processing and analysis of data such as acceleration and attitude angle. At the same time, the standby power consumption of the MPU6050 is only $5 \mu \mathrm{A}$, which can reduce 


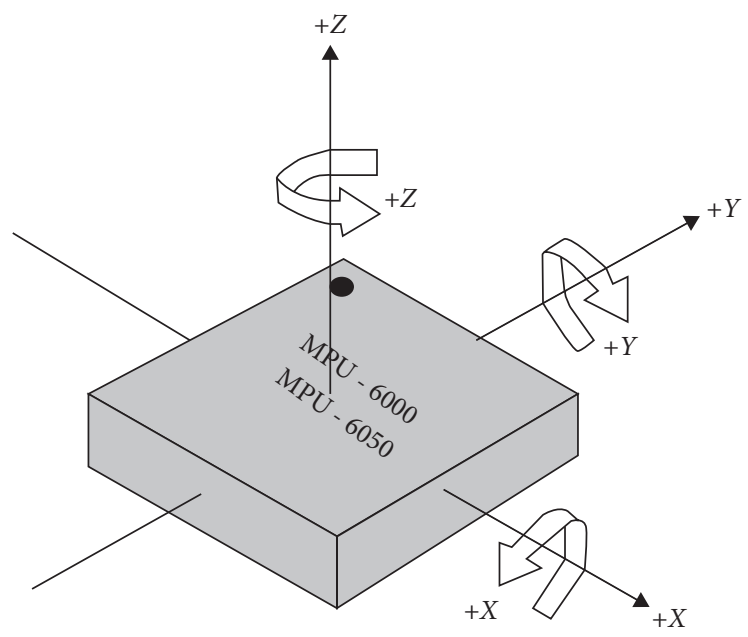

Figure 6: MPU6050 detection axis schematic (the picture comes from https://image.baidu.com/).

TABLE 5: Comparison of wireless transmission technologies.

\begin{tabular}{lcccc}
\hline Specification & Wi-Fi & UWB & ZigBee & LoRa \\
\hline Working frequency & $2.4 \mathrm{GHz}$ & $3.1-10.6 \mathrm{GHz}$ & $2.4 \mathrm{GHz} / 868 / 915 \mathrm{MHz}$ & $433 \mathrm{MHz}-2.4 \mathrm{GHz}$ \\
Transmission rate & $54 \mathrm{Mb} / \mathrm{s}$ & $>480 \mathrm{Mb} / \mathrm{s}$ & $106 / 202 / 424 \mathrm{~kb} / \mathrm{s}$ & $50-424 \mathrm{~Kb} / \mathrm{s}$ \\
Communication distance & $10-300 \mathrm{~m}$ & $<10 \mathrm{~m}$ & $10-1000 \mathrm{~m}$ & $3-15 \mathrm{~km}$ \\
Power consumption & $100 \mathrm{~mW}$ & $1 \mathrm{~mW}$ & $1-100 \mathrm{~mW}$ & $100 \mathrm{~mW}$ \\
\hline
\end{tabular}

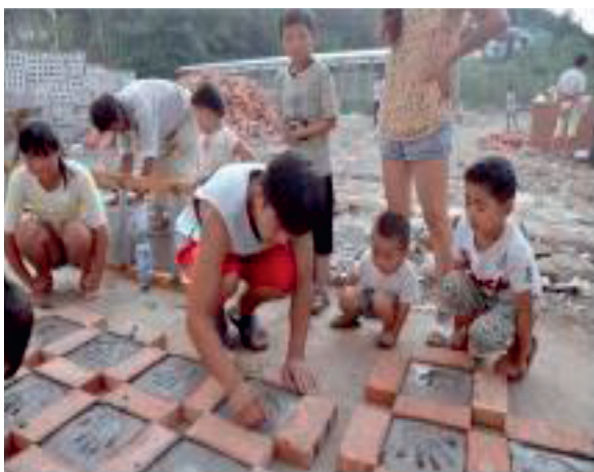

(a)

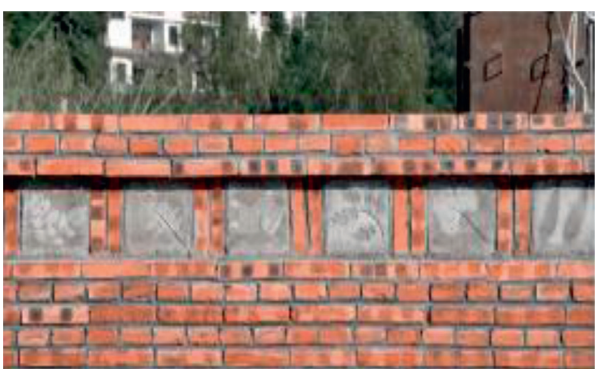

(b)

FIGURE 7: Cultural logo landscape wall (the picture comes from http://bbs.zhulong.com/101020_group).

the power consumption of the data acquisition node and extend the battery life of the node. When the sensor is placed statically and horizontally, except for the $Z$ axis output gravitational acceleration, the value is 1 and the other axis output value is 0. MPU6050 adopts QFN package, and the package volume is only $4 \mathrm{~mm} * 4 \mathrm{~mm} * 0.9 \mathrm{~mm}$, which is convenient for integrated installation.

The performance comparison of various wireless communication technologies is shown in Table 5. The traditional sensor network adopts the wired transmission method. This data transmission method has good stability, but it is difficult to arrange and costly. It cannot even be wired in special environments such as the field and farmland. Once arranged, it cannot be moved. The purpose of this paper is to design a portable, convenient, and versatile nondestructive building deformation monitoring system to solve the problem of inconvenient wiring for most buildings (such as urban high-rise buildings, rural bridges, agricultural greenhouses, and signal transmission towers). The wireless transmission is easy to install, and the network is simple, so this system design uses wireless communication to transmit deformation monitoring data.

As shown in Figure 7, cultural characteristics are soft power and the ultimate vitality provided by industrial development. In the beautiful rural construction plan, we should fully explore cultural characteristics, gather human resources, and form a unique local humanistic identity. For example, in the planning of the construction 


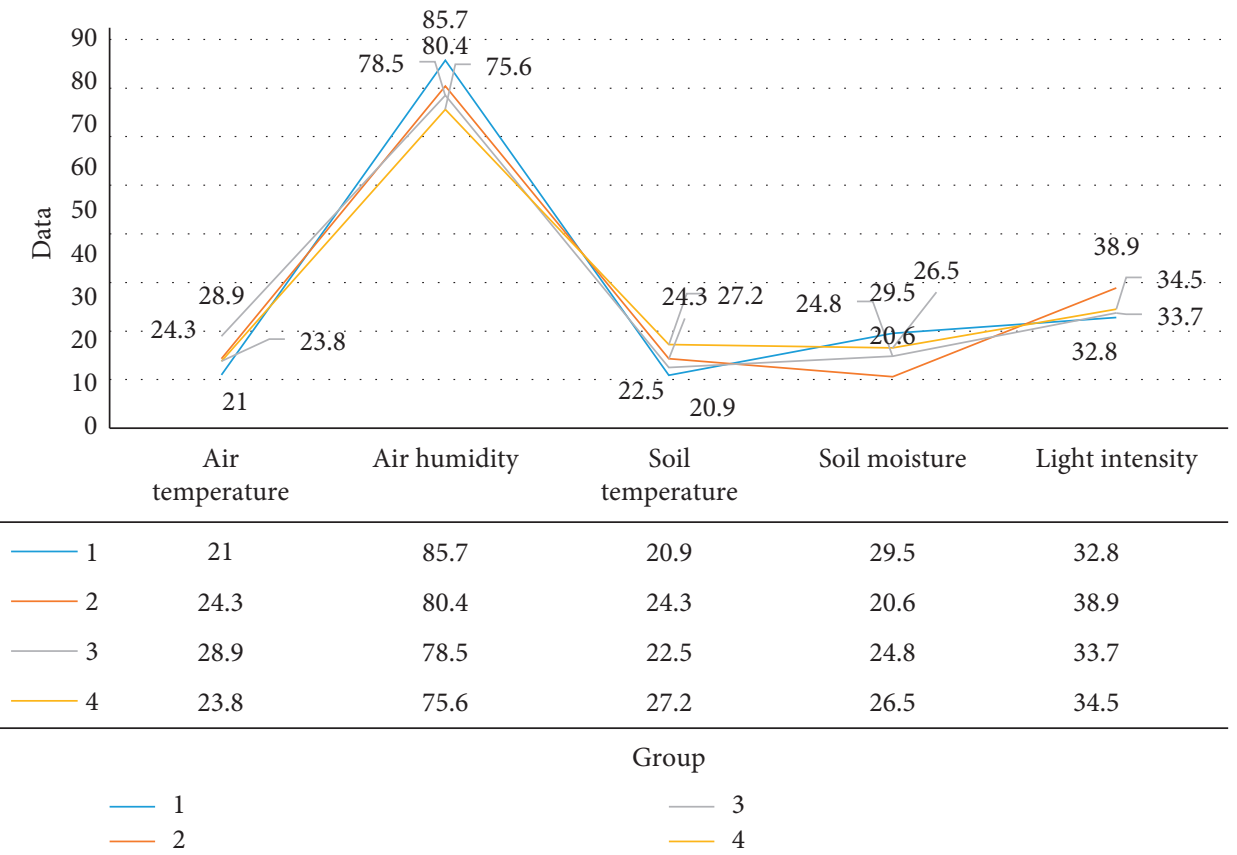

FIgURe 8: Sensor acquisition data.

of beautiful villages, the interaction with villagers can be increased, and the villagers' palm prints, footprints, and native plant prints can be used as the rural landscape wall, which becomes the unique local cultural landmark landscape. The design elements of beautiful rural culture adopt local traditional culture, architecture, costumes, folk customs, farming, and lifestyle. Through the use of regional vernacular elements, the rural cultural landscape is more cordial and rich in regional characteristics. Appropriate retention of these elements and symbols can enhance people's sense of neighborhood, cohesion, and belonging and integrate rural historical and cultural landscape resources into modern rural life through the way of entertaining and entertaining.

As shown in Figure 8, based on the large amount of information, complex environment, weak signal, and other issues encountered in the process of farmland information collection, the significance of the use of multisensor data fusion processing technology is proposed, and the three fusion categories are explained in detail. An improved multisensor adaptive weighting algorithm based on the idea of data-level fusion is proposed.

\section{Conclusions}

Nowadays, with the rapid development of learning technology, using the development level of science and technology to improve the level of China's agricultural development is an important foundation for improving the quality of life of our nationals and the country's economic strength. Through a large number of collections and readings of the characteristic town's era background and relevant basic data, this article explores the meaning of characteristic towns, location selection, industrial characteristics, resident composition, and functions using literature research methods, field survey methods, and comparative research methods. The characteristic development characteristics of structure, cultural resources, natural resources, and so on sum up the natural and artificial design elements of the characteristic town landscape planning. This research is based on responding to the precision agriculture development strategy implemented by the country and designed a green building information monitoring system based on Internet of Things technology. The monitoring system includes information collection terminals, LoRa gateways, and information monitoring terminals. The collected building data are sent to the monitoring terminal. Although the agricultural building deformation monitoring system designed in this paper has basically reached the expected performance, the system has been tested in different environments. The test results basically meet the requirements of rural building deformation monitoring. The motion sensor is used by the hardware system, although the system can meet the demand to complete data collection, the accuracy has not reached the ideal value, and the data fluctuate slightly; we can use more advanced sensors or use multiple sensors for differential measurement. To obtain more accurate information, these applied research studies are gradually changing people's lives and various fields in production and will certainly have broad application prospects. However, due to my professional level and experience limitations, this system still has many shortcomings and still needs to continue to improve in the later stages.

\section{Data Availability}

No data were used to support this study. 


\section{Conflicts of Interest}

The author declares that there are no conflicts of interest.

\section{Authors' Contributions}

The author read and approved the manuscript.

\section{References}

[1] B. Ren, J. Lu, and X. Cao, "Research on the application strategy of green building technology in the construction of characteristic towns," Building Energy Efficiency, vol. 47, no. 3, pp. 36-40, 2019.

[2] Puliqun, "The "special" countermeasures of landscape architecture in the construction of characteristic towns: taking the landscape design of Aheya characteristic towns as an example," China Investigation \& Design, vol. 317, no. 2, pp. 87-91, 2019.

[3] F. Xiao, L. Lei, and S. Lin, "The basic green building design climate-responsive design strategies for form and space," Architecture Journal, pp. 100-104, 2019.

[4] L. Li and W. Zhong, "The application of regional culture in the landscape of characteristic towns," The Classic of Mountains and Seas: The First Half of the Month, vol. 3, no. 5, p. 212, 2017.

[5] C. Li, S. Zhang, P. Liu, F. Sun, J. M. Cioffi, and L. Yang, "Overhearing protocol design exploiting intercell interference in cooperative green networks," IEEE Transactions on Vehicular Technology, vol. 65, no. 1, pp. 441-446, 2016.

[6] W. Zhong, "The application of green building technology in the landscape design of characteristic towns," Ju She, vol. 1, no. 1, p. 97, 2018.

[7] F. Liu, "Talking about the application of green building technology in the landscape design of characteristic towns," Agricultural Science and Technology and Information, vol. 1, no. 15 , pp. 39-41, 2018.

[8] J. Guo, "The application of green building technology in the design of characteristic towns," China Real Estate Industry, vol. 1 , no. 1, p. 63, 2019.

[9] Q. Xu, G. Sheng, and X. Xu, "A summary of theoretical research on smart featured towns," Modern Business, vol. 582, no. 29, pp. 82-84, 2020.

[10] "A comparative analysis of the construction paths of featured towns in the Internet of things-also on the supply of human resources in the towns," Journal of Hunan University of Science \& Technology (Natural Science Edition), vol. 40, no. 11, pp. 68-69, 2019.

[11] J. Li and Q. Xu, "Entrepreneurship in high-tech: promoting innovation and development through the construction of characteristic towns," Hangzhou Science and Technology, vol. 2, no. 2, pp. 26-29, 2016.

[12] J. Xu, "Research on the mode of building cultural squares in small towns with chinese characteristics and integrating modern commerce," Management and Technology of Small and Medium-sized Enterprises (Late Edition), vol. 504, no. 5, pp. 78-79, 2017.

[13] X. Lin, J. Li, and X. Zhang, "Internet + characteristic town application research," Intelligent Building, vol. 000, no. 10, pp. 31-35, 2017.

[14] C. Pan, "The application of green building technology in the landscape design of characteristic towns," Architectural Engineering Technology and Design, vol. 30, no. 25, pp. 475-764, 2017.
[15] L. Sun, "The application of green buildings in the construction of characteristic towns," Housing Industry, vol. 000, no. 3, pp. 36-39, 2017.

[16] Q. $\mathrm{Li}$, "Research on the application of plant landscaping in the landscape design of characteristic towns," Agricultural Technology and Equipment, vol. 20, no. 9, pp. 46-47, 2019.

[17] B. Tu and M. Duan, "Planning practice of characteristic towns based on landscape first-taking the conceptual planning of rose valley in China as an example," Chinese Landscape Architecture, vol. 35, no. 4, pp. 75-80, 2019.

[18] J. Hu, Q. Huang, and G. Guo, "Research on the landscape design of featured towns based on the design concept of Shengyuan," Industrial Design, vol. 000, no. 11, pp. 76-78, 2019.

[19] J. Tai, "Research on the landscape design of featured townsthe mutual relationship between the industrial types of featured towns and landscape planning and case analysis," Northern Architecture, vol. 4, no. 4, pp. 28-34, 2019.

[20] E. Li, "Research on the design method of intelligent buildings based on the internet of things," Building Materials and Decoration, vol. 30, no. 8, pp. 297-298, 2018.

[21] Z. Lv, X. Li, W. Wang, B. Zhang, J. Hu, and S. Feng, "Government affairs service platform for smart city," Future Generation Computer Systems, vol. 81, pp. 443-451, 2018.

[22] H. Elhoseny, M. Elhoseny, A. M. Riad, and A. E. Hassanien, "A framework for big data analysis in smart cities," in Proceedings of the International Conference on Advanced Machine Learning Technologies and Applications (AMLTA2018), pp. 405-414, Cairo, Egypt, February 2018.

[23] L. Zhao, "Research on the landscape planning and design of characteristic towns from the perspective of ecological culture," Popular Literature and Art, vol. 490, no. 16, pp. 118-119, 2020.

[24] F. Jiang, "Research on the value of elements in the landscape design of "characteristic town"-taking gannan Hakka culture as an example," Beauty and Times (Urban Edition), vol. 867, no. 10 , pp. 38-39, 2020.

[25] X. Kong and W. Wang, "Landscape design of characteristic towns based on the concept of three-life integration-taking the cherry blossom theme town in Pei county as an example," Popular Literature and Art, vol. 444, no. 18, pp. 76-77, 2018.

[26] J. Zhao, "Research on the application of the internet of things in the design of intelligent buildings," Automation and Instrumentation, vol. 000, no. 6, pp. 160-161, 2017.

[27] X. Zheng, "Research on the application of the internet of things in the design of intelligent buildings," Communication World, vol. 5, no. 1, pp. 115-116, 2018.

[28] L. Wang, "On the importance of green buildings in the construction of characteristic towns," Green Building Materials, vol. 131, no. 1, p. 248, 2018.

[29] N. Zhou, J. Li, and Y. Yang, "Urban landscape lighting intelligent control system and its application based on internet of things technology-taking Shanghai Hongkou north bund landscape lighting improvement project as an example," Illuminating Engineering Journal, vol. 31, no. 5, pp. 145-150, 2020.

[30] W. Wu, Y. Zheng, Z. Wang et al., "Research on the protection and planning and design of the cultural landscape of characteristic towns-taking Shibi town as an example," Decoration, vol. 316, no. 8, pp. 144-145, 2019.

[31] "Green wall-design of intelligent wall planting system based on Internet of things," Information Technology Education in Primary and Secondary Schools, vol. 215, no. 11, pp. 67-70, 2019. 
[32] Z. Wang, "On the planning strategy of characteristic town ecological landscape system," Ecological Environment and Protection, vol. 1, no. 4, pp. 1-2, 2018.

[33] Z. Lv, B. Hu, and H. Lv, "Infrastructure monitoring and operation for smart cities based on IoT system," IEEE Transactions on Industrial Informatics, vol. 16, no. 3, pp. 1957-1962, 2020.

[34] M. Jia, "Research on the streetscape construction of small towns from the perspective of "characteristic towns"” Beauty and Times (Urban Edition), vol. 707, no. 6, pp. 31-32, 2017.

[35] T. Sun, "Research on the design of information platform for smart park based on the internet of things," Electronic Components and Information Technology, vol. 4, no. 7, pp. 89-90, 2020. 